\title{
On the Artistic Development of Wushu Routine from the Perspective of Communication
}

\author{
Zhang Fan \\ Department of martial arts, Chengdu Sport University, Chengdu, Sichuan, China \\ Email:752189467@qq.com,
}

Key words: Imagery; Wushu routine; Artistry

Abstract: In this paper, the use of literature, logical analysis and other research methods, from the perspective of the image of martial arts. Research shows that people of Wushu thinking mode is the construction and molding of imagery thinking based on Chinese traditional thinking inertia, plays an indispensable role in art development of wushu. With the change of culture, the development of "art", which has a strong post-modern flavor, is rising rapidly, and it has a certain impact on the traditional aesthetic style and aesthetic pursuit. The art of Wushu should be the choice of the times of Wushu development, the historical mission entrusted by the times to the heritage of Wushu, and the highlight of the Chinese martial arts.

\section{Introduction}

Since the martial arts research attracted the attention of scholars, analyzes the different dimensions of the yet to martial arts culture development view is contradictory and confused. The traditional martial arts through thousands of years of national culture, inherit the traditional excellent culture gene, with its rich cultural connotation and the martial art system as the main content, and become the foreign exchange "name card", in the world already has a certain attraction and influence. In this paper, from the perspective of Wushu routines, the use of its artistic development trends, analysis of the development of contemporary Wushu in the face of doubts and confusion, with a view to the development of martial arts to make a new decision.

\section{Wushu Routine Art Development Research Status}

With the transformation of the improvement of people's living standards and the needs of the society, people's understanding of the non-material culture gradually tend to the visibility and expressiveness, as Wushu is the Chinese nation unique body language and symbols, is one of the carrier of culture, which contains rich connotation and the traditional mode of thinking, is a doping of attack and defense and ethics body art. Wushu routine is based on the survival instinct of human being and the refining of the social practice, which is rooted in the Chinese people's unique subjective consciousness and thinking mode. Thinking China traditional image created the Chinese nation "art is supreme" [1] all aspects of cultural identity, and that this is in pursuit of consciousness of social life, reflect the national culture China unique artistic plot and artistic pursuit.

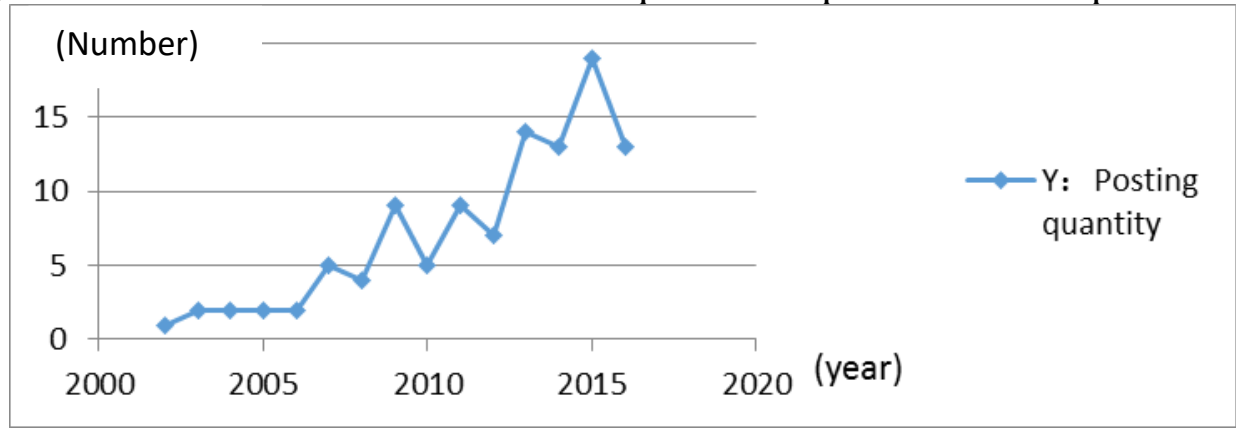

Figure 1 Nearly 15 Years on the Development of Martial Arts Related Research Statistics

In Figure 1 shows the related research about the recent "martial arts development", it is not difficult to find, with the passage of time, people increasingly pay more attention to the artistic development of martial arts, especially the amount of papers published in 2015, up to 18 . The data 
show that not only the cultural field of Wushu has been gradually developed, but also the combination and match between Wushu and interdisciplinary field, which has promoted the spread and popularization of wushu. Wushu not only implies the art meaning of rich and traditional culture, but also reveals the diversity of artistic value and aesthetic perception, to a certain extent, people living in the modern society, are more likely to accept the art of Wushu routine as the carrier and developed.

\section{Development of Wushu Routine}

The social group for Chengdu Sport University students, practitioners of the martial arts in Wuhou District for the interview, to draft the questionnaire, a total of 220 questionnaires (students and 100 copies, 20 copies of various social groups of experts questionnaire), 215 questionnaires were collected, the recovery was $98 \%$, according to the investigation of the cause of population education work with factors such as the removal of 7 invalid questionnaires, 208 valid questionnaires, the effective questionnaire was $95 \%$.

Table 1 Survey of Modern Wushu Development

\begin{tabular}{ccc}
\hline & Support Number & Proportion(\%) \\
\hline Gentle Development & 72 & 35.61 \\
Difficulty Development & 108 & 51.92 \\
Actual Development & 28 & 13.46 \\
Total & 208 & 100.00 \\
\hline
\end{tabular}

American sociologist Berg once said: "now see more and more, the more you see, the more you see, the more you want to see more and more quickly." ${ }^{[2]}$ In the context of information diversity and the era of big data, people's desire for information is gradually increasing, in order to meet the needs of its large amount of information, stop in the cultural surface of the phenomenon is becoming increasingly prominent. According to table 1, the development direction of Wushu routine tends to be difficult, soft and beautiful. The traditional way of thinking and aesthetic point of view with the progress of science and technology and gradually changed, China traditional culture is based on the implicit, conservative and introverted culture as the dominant ideology, in the form of action emphasizes diversity and unity, balance, symmetry, harmony and beauty, in the exercise of skill on the constant pursuit of innovation, with strong rhythm, change to cause people visual pleasure, more emphasis is its intrinsic beauty and reflects the artistic conception and martial arts exercise emotion conveyed. Through the visual culture on the long-term infiltration and influence, to examine its aesthetic intuitive point of view, it is revealed and the western sports visual aesthetic thought fit "difficult new atmosphere".

\section{Martial Arts Method Resolution}

4.1 The Imagery Thinking of the Routine: Observing Objects to Acquire Images. Chinese people have always followed the traditional thinking inertia, there is no lack of Oriental culture of perceptual thinking, can be called "image "image thinking". Its essence is the main with image memory, and through the analysis and research, formed in the inner image of thinking of things, which provides the unique expression of the ancient art form and style Chinese. The formation of Wushu routines is attributed to the excavation and exploration of "image", and the stereotyped thinking mode will take the perceptual cognition of the image taking into full play. The reason why the image can be expressed and understood is inseparable from the cultural context and historical tradition, which is defined and restricted by the image." ${ }^{[3]}$ The integration of the martial arts movement posture and the creation motive, causes the martial arts routine and the traditional "imagery thinking" to have the close correlation.

Chinese view image from the traditional concept of thinking is derived from the Chinese "heaven, all things in consistency", in the primitive society, people's production activities is to rely on the intuitive understanding and simple way to use objects from manual feeding, struggle with the huge beast and beast and dodge from memory the brain attack, refining and summarized, to become their 
own instinct movement is, due to the action of accumulation, and gradually formed a complex and huge system. So far, the spread of body movements has become a fixed martial arts routines, routines in the process of drilling, still need to create a "sense" of the environment "image" action stereotypes. Therefore, boxing players highly pay attention to the emerging phenomenon of nature and fusion of the "image" of cognition, which makes the description of the image show the style and features of body movements.

4.2 Routine Art Show: "Play" and "Practice". In the long history of the development of Wushu routines, it is always accompanied by the theory of "playing" and "practicing". Martial arts rhythmic rhythm, rich in content, has a unique oriental culture and classical beauty. Considerations on the "play" on the level of Wushu and the analysis, with a strong color of the performing arts of Wushu is to emphasize and highlight its unique and artistic, every move of each type is trying to explain its objectives, in a virtual, impressionistic behavior, showing a scene of the attack and defense drills. To give audience to integrity as the aesthetic pleasure. In the "practice" the perspective of Wushu, the ultimate goal is to make the characteristics of the body movement to the enemy the most simple and direct methods. "The biggest difference lies in and play", "practice" the focus is practical, is the use of force and retractable freely, and the "practice" is the center of gravity of the shape of the stretch, coherence and gentle action. The two presents the development trend of difference, the reason is the collision or local culture and foreign culture of fruit, or the gradual development of aesthetic consciousness, or bottom of the rich and innovative era.

\section{The Influence of Artistic Development on the Spread of Wushu Culture}

The creation of Wushu routine is based on the continuous understanding and cognition of the action, so that it has a comprehensive, rigorous offensive and defensive skills system. The Chinese culture through thousands of years of accumulation and sublimation, the diversified development of martial arts show "All flowers bloom together." situation, coupled with the martial arts has folk "grassroots properties", and China traditional culture is a form of martial arts bound together in a common cause, especially the martial arts, is engraved with the regional culture, national culture, humanities and other factors the formation of wushu. Artistic development of wushu simulation and display, to a certain extent, provides a good development trend for the spread of martial arts with the platform.

Table 2 the Influence of the Development of Wushu Art on Wushu Communication

\begin{tabular}{ccc}
\hline & Quantity & Proportion \\
\hline $\begin{array}{c}\text { Promote Wushu } \\
\text { communication }\end{array}$ & 176 & 84.61 \\
Hinder the spread of Wushu & 32 & 15.38 \\
Total & 208 & 100.00 \\
\hline
\end{tabular}

The art of Wushu development has double dimensions of understanding, on the one hand, martial arts exaggerated and soft landscaping, to a certain extent and contemporary people's values fit, provides a good platform for the popularization of Wushu culture. On the other hand, the artistic development of martial arts makes Wushu out of the essence. It has different views to martial arts in the process of propagation. Therefore, it is very important to analyze the micro factors that promote and hinder the spread of Wushu culture. According to table 2 shows, it is not difficult to find that, with reference to the current value orientation and social needs, the proportion of the identification of the artistic products is gradually increasing, and the artistic development of Wushu routine is not surprising.

\section{Conclusion}

Development of Wushu is with the development of the human demands of innovation in contemporary art, culture background, artistic features prominent martial arts is transient and of the times. "Art is produced in order to meet the aesthetic needs of people, without considering its practical value, which makes people in the creation of art have full freedom, to create a highly aesthetic quality of art." ${ }^{[4]}$ In the course of the evolution of Wushu, it is precisely because of its 
own characteristics of the culture of fighting and fighting, which lays the foundation for the artistic characteristics of the body culture. Therefore, it is not surprising that Wushu routines derive formal and intuitive artistic features. It is of great practical significance to explore and understand the cultural attribution and influencing factors of Wushu routines in the contemporary development, and to scientifically define the development trend of wushu.

\section{References}

[1] Chen Zhenyong, Du Chunlin. Research on the essence of Chinese Wushu routines from the perspective of expressionism [J]. Chinese sports science and technology, 2013,02:69-75.

[2]. The reality of the social construction of Bilderberg [M]. Wang Yong. Beijing: Peking University press, 2009.

[3] Zhang Di. Aesthetic interpretation and development trend of Wushu routine [J]. Chinese Martial Arts (Research), 2011,05:26-28+32.

[4] Hu Xiao Ming. On the relationship between sports and art [J]. sports science, 2008,28 (10): 3-8. 